\title{
Lateral Lenticulostriate Artery
}

National Cancer Institute

\section{Source}

National Cancer Institute. Lateral Lenticulostriate Artery. NCI Thesaurus. Code C32940.

The arteries branching off of the horizontal or M1 segment of the middle cerebral artery

in both hemispheres that supply the caudate nucleus and lentiform nucleus. 